\section{Disconnecting occipitoreticular projections: Amnestic effects on a visual habit in the rat*}

\author{
MARSHA A. HOWZE and ROBERT THOMPSON \\ Louisiana State University, Baton Rouge, La. 70803
}

Rats previously trained on a horizontal-vertical discrimination problem showed a significant deficit in retention following bilateral longitudinal knife cuts situated between the lateral cerebral peduncle and the midbrain reticular formation. Similarly placed incisions produced no significant effect on retention of a nonvisual (kinesthetic) discrimination problem. These results further support the notion that an occipitoreticular pathway (which leaves the lateral portion of the cerebral peduncle at nigral levels to terminate in the brainstem reticular formation) is involved in the performance of discriminative responses to visual cues.

In the albino rat, an occipitoreticular pathway has been described which takes a course through the lateral portion of the cerebral peduncle and, at approximately the level of the substantia nigra, begins to leave the peduncle at right angles to terminate in the nucleus cuneiformis of the mesencephalic reticular formation, as well as in the nucleus reticularis pontis oralis (Valverde, 1962). That the integrity of this particular occipitofugal pathway may be necessary for normal retention of a visual pattern discrimination habit is suggested by the findings that bilateral lesions of the occipital cortex (Horel, Bettinger, Royce, \& Meyer, 1966; Lashley, 1931; Thompson, 1969), lateral half of the pedunculo-nigral area (Thompson \& Craddock, 1972), basolateral portion of the nucleus cuneiformis (Thompson, 1965), or nucleus reticularis pontis oralis (Thompson \& Henderson, 1971) leads to profound deficits in retention of a horizontal-vertical discrimination habit.

The purpose of the current study was to determine whether longitudinal knife cuts situated between the lateral pedunculo-nigral area and the nucleus cuneiformis (which would partially disconnect the occipitoreticular pathway in question) would also lead to a significant loss in retention of a horizontal-vertical discrimination habit. For comparative purposes, the retention of a nonvisual (kinesthetic) discrimination habit was investigated following similarly placed knife cuts. On the basis of a previous report (Thompson \& Craddock, 1972), it was expected that the visual habit would be more susceptible to interference by these incisions than the kinesthetic habit.

\section{METHOD}

Adult male albino rats of the Wistar

*This study was supported in part by USPHS Grant MH 08377 . strain were trained in a Thompson-Bryant (1955) discrimination apparatus to choose a horizontal black and white striped card (positive) in preference to an adjacent vertical black and white striped card (negative). Under the motive of escape from footshock, an approach response to the unlocked positive card admitted $S$ to the goalbox, whereas an approach response to the locked negative card was automatically punished by mild shock to the feet. Eight trials were given daily, with an intertrial interval of $60 \mathrm{sec}$, and the positive card was switched from the right to the left window in a strict double-alternation sequence. The criterion of learning consisted of at least 15 correct responses in 2 successive days. Upon reaching the criterion, one group (Group LCP) sustained one-stage bilateral longitudinal cuts which were intended to penetrate the lateral portion of the cerebral peduncle at nigral levels, while a second group (Group OC) sustained cuts which were intended to be either dorsal or anterior to the lateral pedunculo-nigral area-this group served as the operated controls. A third group (Group NC) of three Ss constituted the normal controls. All longitudinal incisions were accomplished by attaching a small ophthalmic knife $(1.75 \mathrm{~mm}$ wide) to the stereotaxic instrument and inserting it vertically through the neocortex to the desired depth. In most cases, the knife was either oscillated $0.5 \mathrm{~mm}$ or reinserted to produce an incision of approximately $2.0 \mathrm{~mm}$ in length in the A.P plane. After a recovery (or rest) period of 14-21 days, all Ss were given a retention test which consisted of relearning the horizontal-vertical discrimination habit. Retention was measured in percentage error savings scores.

Additional Ss were initially subjected to enucleation of the eyes under deep chloral hydrate anesthesia.
After a 2-day recovery period, they were trained on an incline box (kinesthetic) problem under the motive of escape from footshock to choose the arm that was inclined upward and avoid the arm that was inclined downward. The specific details of the apparatus and procedure may be found elsewhere (Thompson, Lukaszewska, Schweigerdt, \& McNew, 1967). Following learning (at least 15 correct responses within 2 successive days), one group sustained incisions like those described for Group LCP and four Ss served as the normal control group. The retention test was given 14-21 days later and consisted of releaming the kinesthetic habit.

Histological verification of the locus and extent of the lesions was carried out in a manner fully described elsewhere (Thompson, 1969). Of the $30 \mathrm{Ss}$ in this study receiving incisions through the lateral pedunculo-nigral area, 21 were discarded because their lesions encroached upon the lateral geniculate bodies, produced necrosis of the pretectal area or hippocampus (due to vascular interruption), or were grossly asymmetrical in the lateral plane. The remaining 9 Ss sustained bilateral incisions which began at the level of the lateral geniculate bodies and extended caudally to the level of the anterior half of the substantia nigra.

\section{RESULTS}

Transient postsurgical effects of the knife cuts included head canting, circling locomotion, pupillodilation, and aphagic-adipsic disorders. By the end of the first postoperative week, however, these Ss were virtually indistinguishable from the normal controls in general behavior and were subsequently found to be excellent runners in the apparatus during the entire retention test. Figure 1 illustrates the extent of the incisions in four animals at the level of the substantia nigra.

With respect to the visual habit, the three Ss of Group NC earned savings scores of $86 \%, 94 \%$, and $100 \%$ (mean $=93.3 \%$ ), while the six Ss of Group OC achieved savings scores ranging from $56 \%$ to $100 \%$ (mean $=$ $84.3 \%)$. In contrast, one $S$ in Group LCP earned a savings score of $71 \%$, but the remaining four achieved savings scores below $39 \%$ (mean = $39.6 \%)$. The Mann-Whitney test disclosed that Group LCP was inferior to Group NC ( $p<.05)$ and Group OC $(\mathrm{p}<.01)$ in retention of the horizontal-vertical discrimination habit. No significant difference was found between the latter two groups.

Concerning the kinesthetic habit, al four control Ss earned savings scores of $100 \%$. Of the six experimental Ss, only four were found to have incisions 


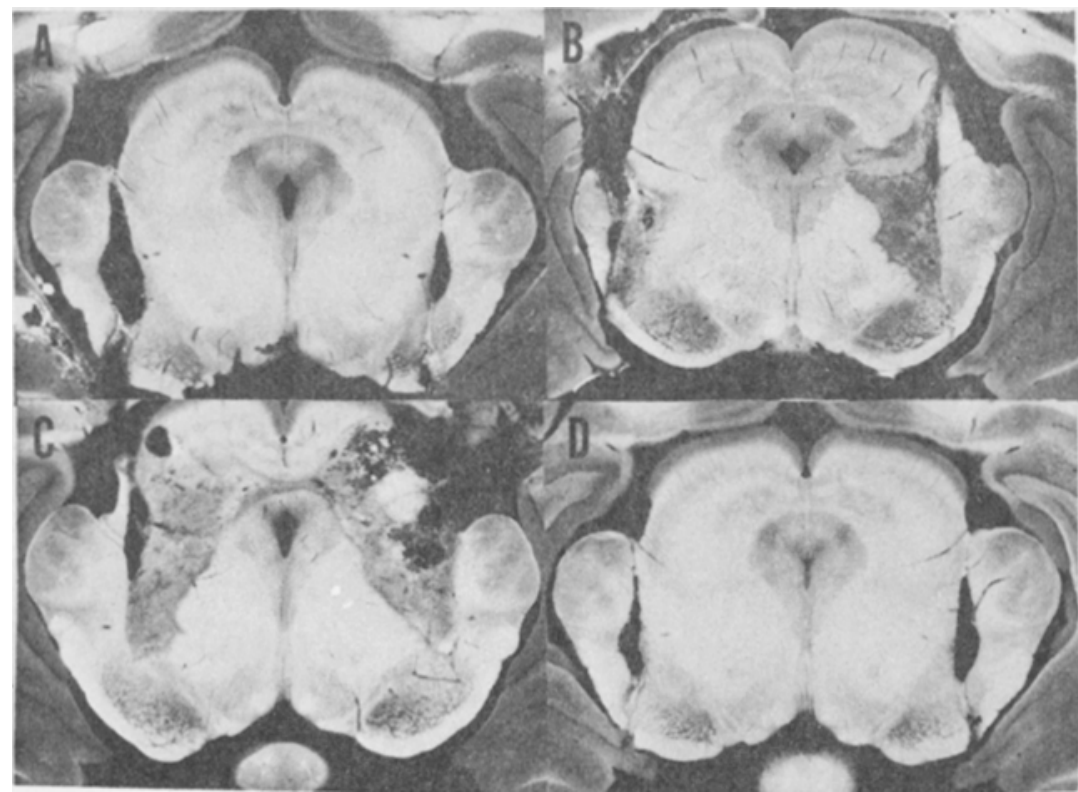

Fig. 1. Photographs of unstained sections showing incisions through the lateral pedunculo-nigral area in two rats ( $A$ and $B$ ) tested on the visual habit (savings scores were $27 \%$ and $26 \%$ ) and one rat (D) tested on the kinesthetic habit (savings score $=83 \%$ ), and incisions dorsal to the lateral pedunculo-nigral area (C) in one rat tested on the visual habit (savings score $=71 \%$ ).

which penetrated the lateral pedunculo-nigral area. These Ss achieved savings scores ranging from $74 \%$ to $100 \%$ (mean $=89.2 \%)$. The remaining two $S$ s (which suffered incisions dorsal to the lateral pedunculo-nigral area) earned savings scores of $67 \%$ and $100 \%$. Neither of these operated subgroups (nor the entire experimental group) was significantly inferior to the normal control group in retention of the kinesthetic discrimination habit.

A comparison between the "kinesthetic" group and the "visual" group, having incisions through the lateral pedunculo-nigral area, revealed that the latter was inferior to the former in savings scores $(\mathrm{p}<.05$ )-there was no overlap between the two groups.

\section{DISCUSSION}

These results confirm those of a previous experiment (Thompson \& Craddock, 1972) in demonstrating that the integrity of the lateral pedunculo-nigral area is essential for normal retention of a horizontal-vertical discrimination habit in the albino rat. In addition, both studies have provided data which indicate that this brainstem area shows some degree of functional specificity, at least to the extent that significantly greater retention deficits occur on a visual discrimination habit than on a kinesthetic discrimination habit; in found between the two groups in savings scores.

As discussed earliex (Thompson \& Craddock, 1972), the deleterious effects on visually guided behavior resulting from lateral pedunculo-nigral lesions are most probably due to interruption of the occipitoreticular pathway described by Valverde (1962) in the albino rat. The only other recognized "visual" fiber system traversing this brainstem area is the accessory optic system (Hayhow, Webb, \& Jervie, 1960). It is highly unlikely, however, that this system would be involved in visually guided behavior. Damage to the lateral terminal nucleus of this system, for example, has not been found to impair visual discrimination performance in either the rat (Thompson \& Craddock, 1972) or the monkey (Pasik, 1966).

As expected, longitudinal incisions through the lateral pedunculo-nigral area produced considerably smaller retention deficits on the visual discrimination habit than electrolytic lesions of this area (compare the results of the current experiment with those of Thompson and Craddock). We interpret this differential effect in terms of the relatively greater sparing of occipitoreticular fibers by our knife cuts. (Attempts were made to increase interruption of this fiber system by extending the incisions more caudally both experiments, no overlap was than those shown in Fig. 1 , but the Ss involved invariably died prior to the retention test).

Finally, the results of the current study raise the possibility that the visual deficits induced by longitudinal knife cuts through the posterior thalamus (Horel, 1968; Thompson, Truax, \& Thorne, 1970) may in fact be due to interruption of occipitoreticular fibers rather than interruption of geniculothalamic fibers. In all Ss showing retention deficits in the latter study, their incisions invariably extended caudally through the substantia nigra and cerebral peduncle (see Fig. 4 of the Thompson, Truax, and Thorne experiment), whereas those Ss exhibiting normal retention had incisions anterior or dorsal to the lateral pedunculo-nigral area (see Fig. 5 of the same experiment). Similar findings were observed in the current study.

\section{REFERENCES}

HAYHOW, W. R., WEBB, C., \& JERVIE A. The accessory optic fiber system in the rat. Journal of Comparative Neurology, $1960,115,187-215$.

HOREL, J. A. A visual function for the ventral nucleus of the lateral geniculate body. Anatomical Record, 1968, 160 , 367.

HOREL, J. A., BETTINGER, L. A., ROYCE, G. J., \& MEYER, D. R. Role of the neocortex in the learning and relearning of two visual habits by the rat. Journal of Comparative \& Physiological Psychology, 1966, 61, 66-78.

LASHLEY, K. S. The mechanism of vision IV. The cerebral areas necessary for pattern vision in the rat. Journal of Comparative Neurology, 1931, 53, 419-478.

PASIK, T. Extrageniculate vision in the monkey: Critical structure. Federation Proceedings, 1966, 25, 574 .

THOMPSON R Centrencephalic theory and interhemispheric transfer of visual habits. Psychological Review, 1965, 72, 385-398.

THOMPSON, R. Localization of the "visual memory system" in the white rat. Journal of Comparative \& Physiological Psychology Monograph, 1969, 69 (Part 2), 1-29.

THOMPSON, R., \& BRYANT, J. H. Memory as affected by activity of the relevant receptor. Psychological Reports, $1955,1,393-400$.

THOMPSON, R., \& CRADDOCK, S. N. Lateral cerebral peduncle lesions: Amnestic effects on a visual habit in the rat. Psychonomic Science, 1972, 27, 140-142.

THOMPSON, R., \& HENDERSON, T. C Pontine reticular formation lesions: Amnestic effects on learned habits in the rat. Psychonomic Science, 1971, 25, 169-170.

THOMPSON, R., LUKASZEWSKA, I. SCHWEIGERDT, A., \& MCNEW, J. J Retention of visual and kinesthetic discriminations in rats following pretecto-diencephalic and ventral mesencephalic damage. Journal of Comparative \& Physiological Psychology, $1967,63,458-468$.

THOMPSON, R., TRUAX, T., \& THORNE M. Retention of visual learning in the 
white rat following knife-cuts through the posterior thalamus and ventromedial midbrain. Brain, Behavior, \& Evolution,
$1970,3,261-284$

VALVERDE, F. Reticular formation of the albino rat's brainstem cytoarchitecture and corticofugal connections. Journal of Comparative Neurology, 1962. 119 25.53 